\title{
Predicting Participation in Children with DCD
}

\author{
Sara Rosenblum • Batya Engel-Yeger
}

Published online: 13 March 2014

(C) Springer International Publishing AG 2014

\begin{abstract}
Children with developmental coordination disorder (DCD) are characterized by participation restrictions. Participation, a central concept in the International Classification of Functioning, Disability and Health Children and Youth Version (ICF-CY; WHO, 2007), is a dynamic process that occurs between individuals and their environment. The aim of this review is to emphasize the role of early identification of children with DCD as an important factor in predicting their participation in daily life. This review discusses issues such as by whom and how this early identification is achieved, at what point within the developmental sequence and in which contexts, and the parents' role to this process and contribution to their children's participation. Finally, future directions for advancing research and practice towards enhancing the participation of children with DCD are discussed in relation to the children's attendance, belonging and involvement in varied life domains.
\end{abstract}

Keywords Developmental coordination disorder · Parents . Detection $\cdot$ Environments $\cdot$ Screening $\cdot$ Participation

\section{Introduction}

The concept of participation is a major component of the International Classification of Functioning, Disability and

\footnotetext{
S. Rosenblum $(\triangle)$

The laboratory of Complex Human Activity and Participation (CHAP), Department of Occupational Therapy, Faculty of Welfare and Health Sciences, University of Haifa, Mount Carmel, Haifa 3498838, Israel

e-mail: rosens@research.haifa.ac.il

B. Engel-Yeger

Department of Occupational Therapy, Faculty of Welfare and Health Sciences, University of Haifa, Mount Carmel, Haifa 3498838, Israel e-mail: bengel@univ.haifa.ac.il
}

Health- Children and Youths Version (ICF-CY) [1], according to which it is defined as a child's involvement in life situations. When coping with disease, the confluence between the individual's limitations at the level of body function, along with his/her activity limitations and restrictions in participation, determine his/her 'position' on the daily 'functioning dis-functioning' scale and significantly influence his/her well being [2].

A growing body of knowledge confirms that health is achieved, supported and maintained when individuals are able to meaningfully engage in occupations and activities that enable desired or needed participation at home, school/ workplace and community life situations [3]. Satisfactory participation is essential for psychological and emotional well-being as well as for skill development, and contributes to one's life satisfaction and sense of competence.

However, our ability to capture the significance of participation in daily function is not a trivial task due to the complexity and multidimensionality of this concept. King [4••] emphasized the need to consider participation-environmenttask interactions over time, thus providing a dynamic perspective on participation, its influential factors and processes, and resulting benefits. Consequently King remarked on the need to examine participation in-depth across specific life environments (e.g. school, home, community), domains (e.g. play, leisure), activity settings (the places where children/youth 'do things') and contexts ('participation in what?') [4••].

Granlund [5*0] discusses the individual's participation according to three dimensions: attendance, belonging and involvement. While attendance relates to the actual being, belonging and involvement are more closely associated to the emotional atmosphere, that is, the individual's enjoyment of the specific activities performed in the context of his/her participation. The concepts of belonging and involvement are critical to the experience of taking part in everyday activities. While literature regarding the dimension of attendance does 
exist, that which focuses on belonging and involvement is scarce as definition and measurement of these concepts are far more complex and expand beyond the frequency of attendance.

In light of the dynamic complexity and multidimensionality of the participation construct, the question of predicting participation is bound up with the topic of diagnoses among populations at high risk for participation restrictions. One such population is that of children, adolescents and adults with developmental coordination disorder (DCD).

\section{Developmental Coordination Disorder (DCD)}

Previous literature has portrayed children with DCD as individuals who must cope with participation restrictions at home, in kindergarten, school and after school [6-9]. DCD is characterized by marked impairment of motor coordination that significantly interferes with academic achievement and/or activities of daily living [10]. About $6 \%$ of children aged 511 years meet the diagnostic criteria for DCD [10-12], at a gender ratio that varies considerably over studies, while some authors have reported a ratio of 3 boys: 1 girl [13]. As such, DCD is one of the most common neuro-developmental disorders affecting school-aged children [14]. However, this prevalent disorder is still under-recognized [15, 16]. Even today many ambiguities can be found in the definition and diagnosis of DCD within the communities of clinical practitioners and scientific researchers [17॰]. Such ambiguities stem from the complexity of the DCD phenomena - characterized as a hidden disability, and from the literature indicating that DCD often co-occurs with other neuro-developmental disorders, such as attention deficit hyperactive disorder (ADHD), learning disabilities, specific language disabilities and/or autistic spectrum disorders (ASD) $[17 \bullet, 18]$. Furthermore, it was reported that children with DCD frequently show behavioural disorders that may result from their reduced feelings of selfworth and self-esteem, and impaired emotional status, as expressed though anxiety and depression [19,20].

According to the ICF model, several factors influence the participation level of an individual: individual/child factors (such as body functions, preferences and social skills, gender), family factors (such as parent's attitudes, socioeconomic status) and environmental factors (such as social attitudes) [21]. The literature includes comprehensive reviews and metaanalyses that have focused on these factors with respect to the participation restrictions experienced by children with $\operatorname{DCD}[22,23,24 \cdot, 25]$. The literature highlights the relevance of addressing the issue of DCD identification as a means for predicting participation in this population. The question of identification will be discussed in light of the dynamic interface occurring between the individual and the environment. More specifically, the central question is how children with
DCD are identified in various environments with development and how this can empower them and enhance their participation in all three of its dimensions (attendance, belonging and involvement [4]).

The following is a quote from an interview with Avi, a 14year-old boy diagnosed with DCD at age 8 , which reflects the complexity of participation in daily life as experienced by children with DCD:

In sport lessons at school, I sit aside with stomach pains, I have never managed to learn to ride a bicycle without training wheels, because I was afraid.... I tried to learn to swim four times with no success. Things fall out of my hands and get spoiled. I am very slow. Doing things simultaneously is impossible, small things [are difficult for me] to manipulate, there is no point, I don't even try. I can't do simple things, such as preparing a salad. It's very difficult to get organized in the morning. People tell me that I am disorganized. People laugh at me. At home, they say that I should move the walls if I could (because I bump into them). My friend tells me that I always stumble into the same wall; in the classroom - over the chairs. I prefer things with round corners. They do less harm to the body. If I write and listen at the same time, the writing will be very untidy. I sleep a lot. This affects my academic achievements.

Avi's subjective experiences are representative of those of many other children with DCD. Based on the ICF-CY model [1] Avi's body structures/functions (e.g., motor coordination limitations) interact with his ability to perform activities and participate in real-life [1]. The functional and emotional difficulties he describes, as well as his desire 'to be part' of his family and of his social group, and to have the choice and control are clearly emphasized in his remarks. They also reinforce study findings indicating that children with DCD encounter participation limitations in various daily occupational areas, such as self-care, academic tasks, play/leisure activities and social involvement [6-9]. Thus, in considering the complex phenomenon of DCD and its negative impact on children's lives, it is vital to elucidate which factors may play a role in predicting participation across different age groups and life domains.

\section{Detection of DCD in Young Children}

Parents of children formally diagnosed with DCD at 5-7 years of age report that they felt that 'something about their child' was different at a much earlier age. Lingam et al. [26] stated that parents, especially mothers, often noticed delays in achieving early motor skills such as sitting, weight-bearing and walking. However, when they reported their concerns to 
health professionals, they were often dismissed as being overly anxious. Thus, pediatric physicians should be educated about the importance of acknowledging the significance of parental concerns such as these early on. Moreover, access to a brief scale that could be employed by pediatricians during parent-physician interactions would be very useful. Focusing on parents' suspicions when they arise could lead to appropriate follow-up procedures and support early identification of DCD.

Another critical juncture at which DCD may be recognized is in the pre-school stage (ages 3-5), during which time parental concerns usually increase as their child engages with peers more frequently, allowing parents to compare their child's daily performance to that of other children. Despite the critical importance of this stage of development, family physicians lacking sufficient knowledge or experience may disregard the parent's concerns.

Hopefully, pediatricians' awareness may have recently been heightened due to guidelines published in May, 2013 by the American Academy of Pediatrics (AAP) Council on Children with Disabilities on the early identification of motor developmental delays. However, while the Council advises pediatricians to carefully watch how children perform requested tasks, as well as their general posture, play and spontaneous motor functions, specific standardized screening assessments for this purpose are not included.

The following section describes a number of specific brief assessments that may assist in the early identification of children with potential hidden disabilities as DCD.

The Children Activity Scales (ChAS) is a tool for parents (ChAS-P) and educators (ChAS-T) which aims to verify potential DCD among children aged 4-8 [27]. Both versions of the ChAS do not focus solely on manifestations of motor difficulties but also on executive function (EF) deficits in daily life, which substantially affect the function and participation of children with DCD [28-30]. The factor analysis performed as part of the validation process of the ChAS-P and ChAS-T, based on data from 216 parents of children aged 4-8 yielded four factors including fine motor, gross motor, activities of daily living (ADL) and organization in space and time. This last factor emphasizes the importance of $\mathrm{EF}$ as reflected through daily organization abilities of children with DCD which is in accordance with the comprehensive metaanalysis results reported by Wilson and his colleagues [24•]. Moreover, the ChAS-P and ChAS-T reveal coordination deficits in daily function in two primary environments (home, kindergarten/school).

Information garnered from the careful observation of children at play can also assist early identification of DCD. For example, "My Child Play - MCP", a questionnaire for parents of children ages 3-8, was recently developed for this purpose. The MCP evaluates both play participation and specific factors/components as interpersonal interactions, executive functions, play choices and preferences and play possibilities supplied by the environment (see [31] for more details). The MCP showed a distinction between children with DCD and typical peers in both performance and factors scores [unpublished thesis, Mazin, 2012, presented at the national physical therapy conference, Israel, 2012]. Play participation of 30 children aged 4-6, diagnosed with DCD was found significantly inferior compared to that of typical controls. More specifically, significant differences were found between the groups for three out of four MCP factors (interpersonal interaction, EF and play choices and preferences) while no significant differences were found for the play possibilities supplied by the environment.

Interactions between parents and children related to daily routines and ADL constitute an important source of knowledge about the child's functioning that requires the attention of health professionals. A daily morning routine in which the child's inability to perform personal hygiene, eating or dressing tasks in a timely fashion, may cause family stress, negative interpersonal relationships between the child and his parents and even between the parents themselves. Moreover, the repercussions of disrupted and stressful morning routines may influence the child's readiness for academic tasks and learning. Thus, difficulties in daily home routines and ADL performance may influence the participation of children with DCD in family activities at home as well as in their educational and social environments.

Therefore, ecologically valid evaluation tools for use with children with DCD should also reflect the child's performance and participation in daily life and focus on ADL and Instrumental activities of daily living (IADL) deficits [25, 32, 33]. The Do-Eat [34] addresses this need. This performance-based evaluation designed for children ages 58 is accompanied by a parents' questionnaire. The child is asked to perform three tasks in the family's kitchen or similar environments: making a sandwich, making chocolate milk and filling out a certificate of outstanding performance for $\mathrm{him} /$ her-self. Performance is graded by the Do-Eat according to three components: task performance, an analysis of their sensorimotor skills and an analysis of their EF. For example, the preparing chocolate milk task requires the performance of pouring milk into a glass. The sensorimotor skills analyzed include posture and movement relationships, motor planning, bi-lateral coordination, fine- motor coordination and sensation. The EFs analyzed include attention, initiation, sequencing, transition between activities, spatial and temporal organization, inhibition, problem-solving and remembering instructions [34-36].

Children with DCD were found to perform significantly lower on all Do-Eat components when compared to typical peers. Differences between groups were also found for the overall score on the parents' questionnaire [34]. Evaluation of children with DCD with the Do-Eat enables a focus on 
children's strengths and deficits and on planning the appropriate strategies for them and their parents to improve participation at home, control and enjoyment of daily function.

Finally, the difficulties that children with DCD must cope with do not end during early childhood [8]. The $D C D-Q$, a parental questionnaire for children aged 8-14 years, is widely used to identify motor coordination problems among these children [37].

\section{Parent's role in Detecting Signs of DCD and Supporting Participation}

Parents play a major role in providing opportunities for their children to participate satisfactorily. Besides being witnesses to their child's functional abilities and participation in daily life situations, parents are important mediators in the dynamic interplay between their child and his/her environment. Parents report difficulties spanning motor and academic performance, emotional/ behavioural responses and social interaction [38]. Although a family-centred approach has been identified as best practice in pediatric care, the perspective of the parent is often overlooked both in research and in practice [39]. Parents' efforts to seek and access services for their children with DCD were characterized by 'a sense of maternal knowing, an experience of guilt-ridden, exhausting, frustrating, trivialization of the problem, a sense of 'going it alone' and 'getting the run around' [26, 40]. Comments reflected their frustration regarding the insufficient knowledge and expertise of health and education professionals working with children with DCD and the lack of accessible information and high quality support services.

Home and family play a meaningful role in understanding and providing the child with opportunities for satisfactory participation, not only at the level of attendance but also in their enjoyment, belonging and involvement [41•]. Moreover, parents are meaningful agents of change not just regarding their children's participation at home (in ADL, IADL and play) but also in their educational and recreational frameworks. Thus, as parents play a central role in enabling participation of their child, there is a need to develop family-centred support services, providing them with knowledge and developing their awareness of strategies and adaptations that best suits their child's needs [41•].

Parents' contribution to intervention should be supported not only by increasing their awareness of how their child may be helped, but by encouraging them to reach out for the assistance of health providers. For example, physicians should seriously consider what the parents report and their concerns regarding their children. Moreover, a practical, standardized, short questionnaire is needed to document aspects of the participation of very young children at home that could be used by the physician to screen for hidden disabilities such as
DCD. By respecting parents' expertise regarding their child, physicians could enable early recognition of the problem. Early referral of parents to occupational or physical therapists will insure that they acquire the relevant knowledge and strategies needed to enhance their children's motor behaviour as early as possible, and consequently improve their children's future participation and performance [42].

\section{School Participation}

As children and adolescents with DCD often manifest a range of difficulties in their school environment, they should be screened for potential DCD there as well. The main issues in school relate to their actual performance in physical activity lessons, play and leisure participation, and their handwriting production in the academic domain. Moreover, children with DCD are at greater risk for hypoactivity in comparison to typically developed (TD) children and for obesity [43-46]. As one child who was interviewed noted in relation to group sports, 'all the children see'... (my disability, my weaknesses). Thus, he preferred not to participate in such activities.

Information regarding schoolchildren's participation in physical activities can be obtained through the Teacher Estimation of Activity Form (TEAF [47, 48]). This practical, short questionnaire was designed to obtain teachers' assessments of their students' motor abilities, degree of participation in physical activities, and generalized self-efficacy towards physical activity, based on observations made during schoolbased activities [48]. The TEAF would be a useful tool to administer in school by physical activity teachers when they, other teachers or parents' have observed clumsiness or suspect a child of having DCD. Timely identification may prevent measures to avoid participation in school duties and social teams (as described by Avi, for example), as well as signs of poor self-image or affect $[6,49,50]$.

Handwriting deficiency in DCD is another significant factor with respect to participation in academic activities. Considering the central role of handwriting activities for school-aged children [51], the inability to keep pace with class assignments may serve to further amplify the negative attitudes that children perceive from their teachers and classmates, further diminishing their sense of competence [52]. Although children with DCD are at particular risk for handwriting deficiency $[50,53]$, a key element contributing to their academic achievement and self-esteem [53], standardized tools and research concerning handwriting performance among this population are scarce [17॰]. Thus, important information is lost, children's academic participation is impacted and the risk of developing secondary socio-emotional difficulties among this population increases [54-56]. The Handwriting Proficiency Screening Questionnaire (HPSQ) [57] is a 10-item scale that may be useful for this population. 
To complete the picture, the Computerised Penmanship Evaluation Tool (ComPET) may provide deeper insight about the handwriting process of children with DCD (see [58, 59] for more details).

Importantly, recent studies suggest that specific handwriting measures can predict children's and adult's organizational abilities in daily function tasks at home and school $[60,61]$. Handwriting features may be a manifestation of their executive control functioning. The use of such tools may highlight children's needs and suggest suitable adaptations in their typical environments to promote better academic participation and prevent secondary emotional manifestations.

Dahan-Oliel et al. [62] remarked that the ability to participate in leisure activities is a key aspect of wellbeing among children with neuro-developmental disabilities. The literature indicates that school-age children with DCD participate in fewer activities, with less intensity, and in fewer active skillbased and informal activities, compared with children without DCD [7]. Furthermore, their motor abilities significantly predicted their participation diversity in after-school activities and in team sports. This may result in loneliness and impact their subjective quality of life [63, 64].

The Children Leisure Assessment Scale (CLASS, [65]) is a standardized self-report tool for measuring and encouraging discussions about leisure participation among schoolchildren with and without disabilities included DCD [66]. The CLASS includes 40 items, covering six participation dimensions: variety (which activities), frequency (how often), sociability (with whom), preference (how much he or she enjoys the activity), time consumption (how much time is invested) and desired activities (which activities are desired but not currently undertaken). Thus, it encompasses all three participation dimensions suggested by Granlund [4••] -attendance, belonging and involvement - and may serve both as a clinical assessment as well as a tool that can be used for mapping the needs of children with DCD in the community.

\section{Participation Limitations among Adolescents and Adults with DCD}

Participation limitations occur also among adolescents and adults with DCD [67-69]. A number of tools have emerged for this population. Yet, these tools still require further research on larger samples in order to establish their reliability and validity in light of the difficulty of identifying adolescents and adults with DCD. For example, the Adolescents and Adults Coordination Questionnaire (AAC-Q; [69]) that has established cutoff points calculated for DCD in both men and women and may be used to verify the diagnosis of DCD.

Another tool is the Adult Developmental Co-ordination Disorders/Dyspraxia Checklist (ADC; [55]). The ADC is a practical, easy to use self-report questionnaire that provides information about the person's ability to participate within various contexts (such as home, academic and social environments). Its subscales cover a wide age range, beginning with a retrospective consideration of the adult's participation during childhood, through his/her current participation features. Participants were 107 students aged 17 to 42 years, whose self-report as being 'clumsy' was validated according to the DSM-4 criteria's. Results indicated that the ADC correctly classified $88 \%$ of the participants overall; $91 \%$ of the control group, and $84 \%$ of the students with DCD, while the retrospective scale (childhood recollections) supplied the highest contribution to between group discrimination. In their retrospective views of their childhood, $75 \%$ or more of adults with DCD had difficulty learning to ride a bike, playing team games such as football and volleyball, and in catching or throwing balls accurately. More than $65 \%$ reported that they had difficulties in organizing/finding things in their room and writing texts that others could read. When asked about their present daily function, more than $65 \%$ reported that they avoid team games/sports, do not go to a gym and avoid going to clubs/dancing. More than $70 \%$ reported that they have difficulty writing neatly and $60 \%$ required more time than others to learn to drive. In contrast, members of the control group reported percentages ranging from 2-20\% for these same items. Such findings illustrate the importance of early DCD diagnosis to avoid or reduce participation deficits at home, academic and the social environments.

\section{Conclusion}

Children with DCD desire to be similar to their peers, socially accepted and involved in social activities. The ability of children with DCD to successfully integrate with their typical peers and family members and engage in other social relationships is strongly related to the knowledge and attitudes of people around them. Following the above description, early identification is critical for the prevention of emotional sequels related to decreased success and participation in life domains and environments. Consequently, parents and teachers should be recognized as the appropriate source of information about their children/students for early identification; their need to receive knowledge and coaching should be acknowledged, as they serve as children's advocates, mediators and coaches [70, 71].

More knowledge about DCD, its manifestations as well as practical tools for identification need to be disseminated among health care workers and physicians, as well as educators working in kindergartens and schools (Fig. 1). As previously described in relation to the Do-Eat tool, the evaluation process may include both bottom-up and top-down evaluations. Bottom-up evaluations begin with detecting components/body functions and structures required for 


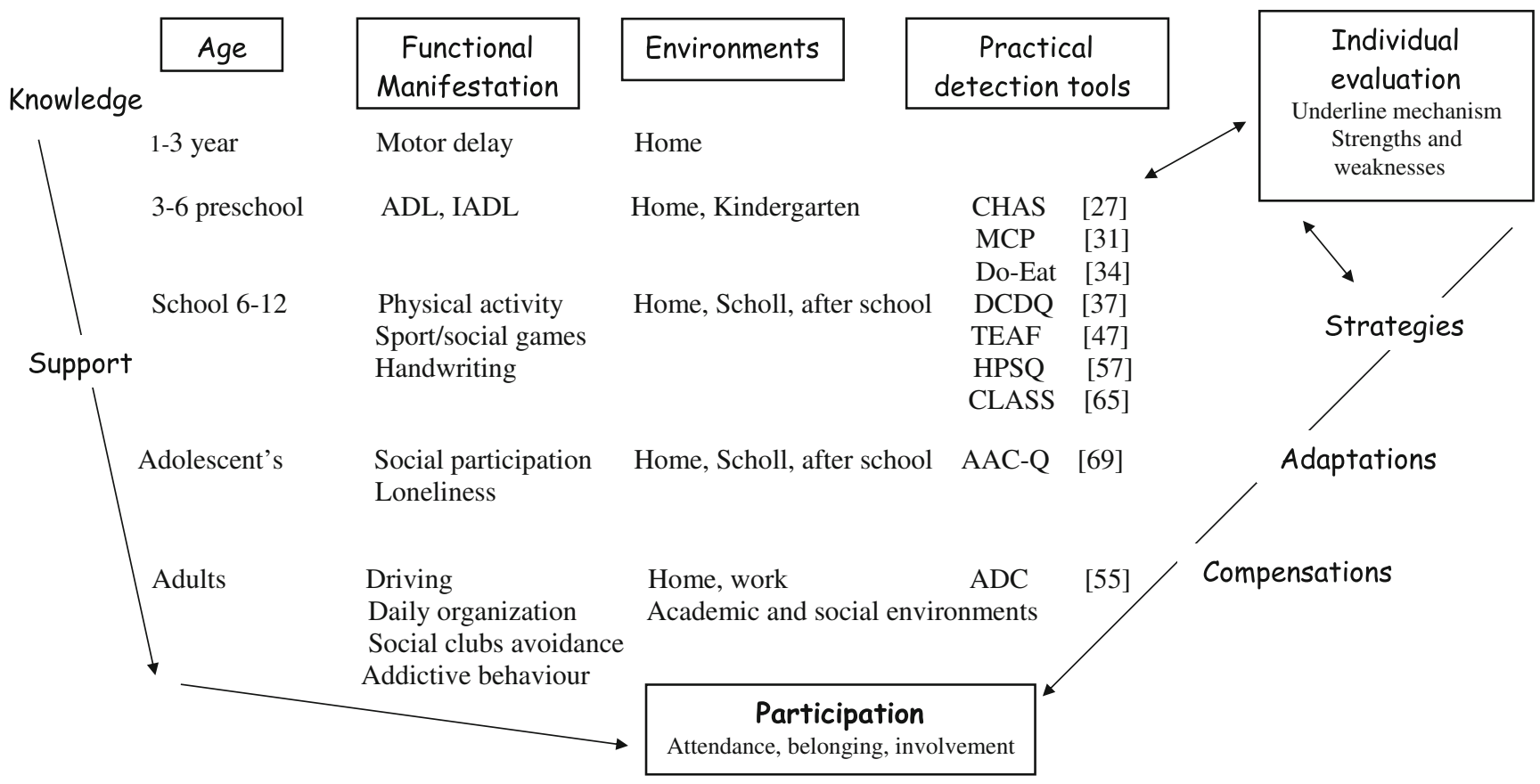

Fig. 1 Towards satisfactory participation among children with Developmental Coordination Disorder

efficient performance such as working memory, fine motor or gross motor ability. Whereas, top-down evaluations, refer to examination of the actual performance characteristics.

Thus, it is recommended to characterize actual performance (activity and participation) as well as investigating the mechanisms related to body functions and structures underlying performance. It is recommended that the assessment process focus not only on children's deficiencies, but on their strengths as well [72], and that the children be provided with the means of expressing their perspective regarding participation [73]. This can be achieved by focusing on children's play and leisure occupations, during which time they participate in activities that they choose to do, rather than those they are required to do. We suggest that children's participation in the intervention process can be encouraged by translating this knowledge to practice.

Consequently, implementation of an ecological theory to daily participation is required as the individual's daily function is profoundly affected by events occurring in his environment [e.g. [74]. The way in which children with DCD perceive and deal with varied environments need to be considered and tools, strategies and adaptations for enhancing children's participation in those environments may be supplied [73, 75]. In the academic domain, teachers could be advised regarding methods to relieve the pressure of having to perform daily tasks/assignments involving handwriting among children with DCD. In after school frameworks, the leisure opportunities available should be carefully considered so that they match the children's abilities and contribute positively to their quality of life [62]. Moreover, since children with DCD tend to play alone, intervention should focus on acquiring social skills in their natural environment, where activities are more meaningful, as in the playground or in team sports. For example, a comprehensive intervention model, Partnering for Change (P4C) was developed by Missiuna and her colleagues [75]. This model focuses on capacity building through multidisciplinary collaboration between therapists, educators and parents in a school-based context aimed to create changes within the child's daily environment in order to promote participation.

In sum, the efficacy of interventions for children and youth with disability should be developed and checked in terms of how they improve, support or optimize participation outcomes [3]. The complexity of the DCD phenomenon and its outcomes, calls strongly for early identification, comprehensive evaluations emphasizing participation across various environments and considers the knowledge supplied by parents, educators and other people significant to the child's involvement in daily life, as well as the child's own self report. To ensure optimal development and participation in these children, intervention should be focused on how to help them develop habits of mind and behaviour that build resilience, enhance success and control and improve their attendance, belonging and involvement in various

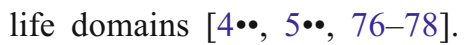




\section{Compliance with Ethics Guidelines}

Conflict of Interest Sara Rosenblum and Batya Engel-Yeger declare that they have no conflict of interest.

Human and Animal Rights and Informed Consent This article does not contain any studies with human or animal subjects performed by any of the authors.

\section{References}

Papers of particular interest, published recently, have been highlighted as:

- Of importance

•. Of major importance

1. World Health Organization. International Classification of Functioning, Disability and Health: Children \& youth version. Geneva: ICF-CY; 2007.

2. Mandich A, Polatajko H, Rodger S. Rites of passage: Understanding participation of children with developmental coordination disorder. Hum Mov Sci. 2003;22(4):583-95.

3. American Occupational Therapy Association. Occupational Therapy Practice Framework: Domain and process. Am J Occup Ther. 2002;56:609-39.

4.• King G. Perspectives on measuring participation: going forward. Child Care Health Dev. 2013;39(4):466-9. Enlarges the meaning of 'participation' as a mutidemetional complex concept which includes varied dimensions need to be taken into account in evaluation and intervention process towards improving participation of children with DCD.

5.• Granlund M. Participation-challenges in conceptualization, measurement and intervention. Child Care Health Dev. 2013;39(4): 470-3. Enlarges the meaning of 'participation' as a mutidemetional complex concept which includes varied dimensions need to be taken into account in evaluation and intervention process towards improving participation of children with $D C D$.

6. Engel-Yeger B, Hanna Kasis A. The relationship between Developmental Co-ordination Disorders, child's perceived self-efficacy and preference to participate in daily activities. Child Care Health Dev. 2010;36(5):670-7.

7. Jarus T, Lourie-Gelberg Y, Engel-Yeger B, et al. Participation patterns of school-aged children with and without DCD. Res Dev Disabil. 2011;32(4):1323-31.

8. Kirby A. Dyspraxia series: part one. At sixes and sevens. J Fam Health Care. 2011;21(4):29-31.

9. Magalhães L, Cardoso A, Missiuna C. Activities and participation in children with developmental coordination disorder: a systematic review. Res Dev Disabil. 2011;32(4):1309-16.

10. American Psychiatric Association. Diagnostic and Statistical Manual of Mental Disorders 4th edition DSM-IV - text revision. Washington DC: Author; 2000.

11. Statistics Canada. Table 051-0001 estimates of population, by age group and sex, Canada, provinces and territories, annual (persons). Statistics Canada; 2006. http://cansim2.statcan.ca/cgiwin/cnsmcgi. pgm?\&Lang $=$ E\&ArrayId $=510001 \&$ Array_Pick $=1 \&$ Detail $=$ $1 \&$ ResultTemplate $=\mathrm{CII} / \mathrm{CII} \&$ RootDir $=\mathrm{CII} /$. Accessed August 2007.

12. U.S. Census Bureau (2006). National population estimates - characteristics. Available from: http://www.census.gov/popest/national/ asrh/NC-EST2005-sa.html Accessed August 2007.
13. Missiuna C, Moll S, King G, et al. Life experiences of young adults who have coordination difficulties. Can J Occup Ther. 2008;75(3): 157-66.

14. Wann J. Current approaches to intervention in children with developmental coordination disorder. Dev Med Child Neurol. 2007;49(6):405.

15. Gaines R, Missiuna C, Egan M, et al. Educational outreach and collaborative care enhances physician's perceived knowledge about Developmental Coordination Disorder. BMC Health Serv Res. 2008;8(1):21.

16. Missiuna C, Gaines R, Soucie H. Why every office needs a tennis ball: a new approach to assessing the clumsy child. Can Med Assoc J. 2006;175(5):471.

17. Blank R, Smiths-Engelsman B, Polatajko H, et al. European Academy for Childhood Disability (EACD): Recommendations on the definition, diagnosis and intervention of developmental coordination disorder (long version)*. Dev Med Child Neurol. 2012;54(1):54-93. This paper presents the most up to date guidelines related future required developments related to $D C D$.

18. Josman N, Rosenblum S. A Meta-cognitive Model for Children With Atypical Brain Development. In: Katz N, editor. Cognition, occupation and participation across the life span : neuroscience, neurorehabilitation and models of intervention in occupational therapy. Bethesda: AOTA press; 2011. p. 223-47.

19. Missiuna C, Rivard L, Bartlett D. Exploring assessment tools and the target of intervention for children with developmental coordination disorder. Phys Occup Ther Pediatr. 2006;26(1-2):71-89.

20. Poulsen AA, Ziviani JM, Cuskelly M, et al. Boys with developmental coordination disorder: Loneliness and team sports participation. Am J Occup Ther. 2007;61(4):451-62.

21. Engel-Yeger B. Comparing participation patterns in out of school activities between Israeli Jewish and Muslim children. Scand J Occup Ther. 2013;20(5):323-35.

22. Polatajko HJ, Cantin N. Developmental coordination disorder (dyspraxia): an overview of the state of the art. Semin Pediatr Neurol. 2005;12(4):250-8.

23. Sylvestre A, Nadeau L, Charron L, et al. Social participation by children with developmental coordination disorder compared to their peers. Disabil Rehabil. 2013(0):1-7.

24. Wilson PH, Ruddock S, Smiths-Engelsman B, et al. Understanding performance deficits in developmental coordination disorder: a meta-analysis of recent research. Dev Med Child Neurol. 2013;55(3):217-28. This paper is a comprehensive up to date meta-analysis about performance deficits among children with $D C D$.

25. Zwicker JG, Missiuna C, Harris SR, et al. Developmental coordination disorder: a pilot diffusion tensor imaging study. Pediatr Neurol. 2012;46(3):162-7.

26. Lingam R, Coad J, Novak C, et al. Identity and empowerment: a qualitative study of teenagers with developmental coordination disorder. Arch Dis Child. 2011;96 Suppl 1:A7-9.

27. Rosenblum $\mathrm{S}$. The development and standardization of the Children Activity Scales (ChAS-P/T) for the early identification of children with Developmental Coordination Disorders. Child Care Health Dev. 2006;32(6):619-32.

28. Alizadeh H, Zahedipour M. Executive functions in children with and without Developmental Coordination Disorder. Adv Cogn Sci. 2005;6(3-4):49-56.

29. Piek JP, Dyck MJ, Nieman A, et al. The relationship between motor coordination, executive functioning and attention in school aged children. Arch Clin Neuropsychol. 2004;19(8):1063-76.

30. Zwicker JG, Missiuna C, Boyd LA. Neural correlates of developmental coordination disorder: a review of hypotheses. J Child Neurol. 2009;24(10):1273-81.

31. Schneider E, Rosenblum S. (2014) Development, Reliability and Validity of "My Child's Play" Questionnaire, Accepted (2.13). Am J Occup Ther. 
32. Summers J, Larkin D, Dewey D. Activities of daily living in children with developmental coordination disorder: dressing, personal hygiene, and eating skills. Hum Mov Sci. 2008;27(2):215-29.

33. Summers J, Larkin D, Dewey D. What impact does developmental coordination disorder have on daily routines? Int J Disabil Dev Educ. 2008;55(2):131-41.

34. Josman N, Goffer A, Rosenblum S. Development and Standardization of a "Do-Eat" Activity of Daily Living Performance Test for Children. Am J Occup Ther. 2010;64(1):47-58.

35. Frisch C, Goffer A, Koren A, Dotan-Schori G, et al. Establishing Construct Validity for the Do-Eat: Discriminating between ages and gender. Isr J Occup Ther. 2009;18:H117-39.

36. Rosenblum S, Josman N, Goffer A. Do-Eat" Activity of Daily Living Performance Test for Children, USA, Maddak Inc, www. maddak.com.

37. Wilson BN, Kaplan BJ, Crawford SG, et al. Reliability and validity of a parent questionnaire on childhood motor skills. Am J Occup Ther. 2000;54(5):484-93.

38. Stephenson E, Chesson R. 'Always the guiding hand': parents' accounts of the long-term implications of developmental co-ordination disorder for their children and families. Child Care Health Dev. 2008;34(3):335-43.

39. Missiuna C, Moll S, Law M, et al. Mysteries and mazes: parents' experiences of children with developmental coordination disorder. Can J Occup Ther. 2006;73(1):7-17.

40. Rodger S, Mandich A. Getting the run around: accessing services for children with developmental co-ordination disorder. Child Care Health Dev. 2005;31(4):449-57.

41. Piškur B, Beurskens AJ, Jongmans MJ, et al. Parents' actions, challenges, and needs while enabling participation of children with a physical disability: a scoping review. BMC Pediatr. 2012;12(1): 177. This manuscript supply a wide perspective about parents needs related to children with disabilities.

42. Missiuna C, Moll S, King G, et al. "Missed and misunderstood": children with coordination difficulties in the school system. Int $\mathrm{J}$ Spec Educ. 2006;21(1):53-67.

43. Cairney J, Hay JA, Faught BE, et al. Developmental coordination disorder, generalized self-efficacy toward physical activity, and participation in organized and free play activities. J Pediatr. 2005;147(4):515-20.

44. Cairney J, Hay J, Veldhuizen S, et al. Trajectories of relative weight and waist circumference among children with and without developmental coordination disorder. Can Med Assoc J. 2010;182(11): $1167-72$.

45. Hands B, Larkin D. Physical fitness and developmental coordination disorder. Dev Coord Disord. 2002: 172-184.

46. Faught BE, Hay JA, Cairney J, et al. Increased risk for coronary vascular disease in children with developmental coordination disorder. J Adolesc Health. 2005;37(5):376-80.

47. Hay JA. Adequacy in and predilection for physical activity in children. Clin J Sport Med. 1992;2(3):192-201.

48. Hay J, Donnelly P. Sorting out the boys from the girls: Teacher and student perceptions of student physical ability. Avante. 1996;2:36-52.

49. Engel-Yeger B, Hanna-Kassis A, Rosenblum S. Can gymnastic teacher predict leisure activity preference among children with developmental coordination disorders (DCD)? Res Dev Disabil. 2012;33(4):1006-13.

50. Faught BE, Cairney J, Hay J, et al. Screening for motor coordination challenges in children using teacher ratings of physical ability and activity. Hum Mov Sci. 2008;27(2):177-89.

51. O'Hare A. Hands up for handwriting. Dev Med Child Neurol. 2004;46(10):651.

52. Engel-Yeger B, Nagauker-Yanuv L, Rosenblum S. Handwriting performance, self-reports, and perceived selfefficacy among children with dysgraphia. Am J Occup Ther. 2009;63(2):182-92.
53. O'Hare A, Khalid S. The association of abnormal cerebellar function in children with developmental coordination disorder and reading difficulties. Dyslexia. 2002;8(4):234-48.

54. Feder KP, Majnemer A. Handwriting development, competency, and intervention. Dev Med Child Neurol. 2007;49(4):312-7.

55. Kirby A, Edwards L, Sugden D, et al. The development and standardization of the adult Developmental Co-ordination Disorders/dyspraxia checklist (ADC). Res Dev Disabil. 2010;31(1):131-9.

56. Rosenblum S, Weintraub N. Learning disabilities and occupational therapy: Review of research and practice as reflected in the IJOT. Isr J Occup Ther. 2007;16(3):H 13758. In Hebrew.

57. Rosenblum S. Development, reliability, and validity of the Handwriting Proficiency Screening Questionnaire (HPSQ). Am J Occup Ther. 2008;62(3):298-307.

58. Rosenblum S, Livneh-Zirinski M. Handwriting process and product characteristics of children diagnosed with developmental coordination disorder. Hum Mov Sci. 2008;27(2):200-14.

59. Rosenblum S, Margieh JA, Engel-Yeger B. Handwriting features of children with developmental coordination disorder-Results of triangular evaluation. Res Dev Disabil. 2013;34(11):4134-41.

60. Rosenblum S. Handwriting measures as reflectors of Executive Functions among adults with Developmental Coordination Disorders (DCD). Front Psychol. 2013;4:357.

61. Rosenblum S, Livneh-Zirinski M. (2014). Do Relationships Exist between Brain-Hand Language and Daily Function Characteristics of Children with a Hidden Disability?.In: Basis S, Esposito A, Morabito FC. (Eds'). Recent Advances of Neural Networks Models and Applications, Proceedings of the 23rd Workshop of the Italian Neural Networks Society (SIREN), May 23-25, Vietri sul Mare, Salerno, Italy.In: Howlett, R. J., \& Jain, L. C. (Eds') Smart Innovation, Systems and Technologies Volume 26 Springer (pp 269-282)

62. Dahan-Oliel N, Shikako-Thomas K, Majnemer A. Quality of life and leisure participation in children with neurodevelopmental disabilities: A thematic analysis of the literature. Qual Life Res. 2012;21(3):427-39.

63. Fong SS, Lee VY, Chan NN, et al. Motor ability and weight status are determinants of out-of-school activity participation for children with developmental coordination disorder. Res Dev Disabil. 2011;32(6):2614-23.

64. Poulsen AA, Ziviani JM, Johnson H, et al. Loneliness and life satisfaction of boys with developmental coordination disorder: the impact of leisure participation and perceived freedom in leisure. Hum Mov Sci. 2008;27(2):325-43.

65. Rosenblum S, Sachs D, Schreuer N. Reliability and validity of the Children's Leisure Assessment Scale. Am J Occup Ther. 2010;64(4):633-41.

66. Schreuer N, Sachs D, Rosenblum S. Participation in leisure activities: Differences between children with and without physical disabilities. Res Dev Disabil. 2014;35(1):223-33. 2014.

67. Cousins M, Smyth MM. Developmental coordination impairments in adulthood. Hum Mov Sci. 2003;22(4):433-59.

68. Kirby A, Sugden D, Beveridge S, et al. Dyslexia and developmental co-ordination disorder in further and higher education - similarities and differences. Does the 'Label' influence the support given? Dyslexia. 2008;14(3):197-213.

69. Tal-Saban M, Zarka S, Grotto I, et al. The functional profile of young adults with suspected Developmental Coordination Disorder (DCD). Res Dev Disabil. 2012;33(6):2193-202.

70. Graham F, Rodger S, Ziviani J. Enabling occupational performance of children through coaching parents: Three case reports. Phys Occup Ther Pediatr. 2010;30(1):4-15. 
71. Novak C, Lingam R, Coad J, et al. 'Providing more scaffolding': parenting a child with developmental co-ordination disorder, a hidden disability. Child Care Health Dev. 2012;38(6):829-35.

72. Cantell MH, Smyth MM, Ahonen TP. Clumsiness in adolescence: Educational, motor, and social outcomes of motor delay detected at 5 years. Adapt Phys Act Q. 1994;11:115-29.

73. Primeau LA, Ferguson JM. Occupational frame of reference. In: Kramer P, Hinojosa J, editors. Frames of reference for pediatric occupational therapy. 2nd ed. Philadelphia: Williams \& Wilkins; 1999. p. 469-516.

74. Bronfenbrenner, U, Bronfenbrenner U. The ecology of human development: Experiments by nature and design. Harvard university press. 2009
75. Missiuna CA, Pollock NA, Levac DE, et al. Partnering for Change: An innovative school-based occupational therapy service delivery model for children with developmental coordination disorder. Can J Occup Ther. 2012;79(1):41-50.

76. Rosenberg L, Ratzon N, Jarus T, et al. Perceived environmental restrictions for the participation of children with mild developmental disabilities. Child Care Health Dev. 2012;38(6):836-43.

77. Greenberg M, Greenberg A. Nurturing Mindfulness in Children and Youth: Current State of Research. Child Dev Perspect. 2012;6(2):161.

78. Liberman L, Ratzon N, Bart O. The profile of performance skills and emotional factors in the context of participation among young children with Developmental Coordination Disorder. Res Dev Disabil. 2013;34(1):87-94. 